\title{
$\operatorname{LASRA}^{\circledR}$
}

NZ Leather \& Shoe Research ACS Spring 2020 National Meeting \& Expo

\section{Rapid and quantitative analysis of collagen crosslinks in skins using a silica hydride column and mass spectrometry detection}

Rafea Naffa, Jakob Gaar, Wenkai Zhang, Margaret Brimble and Joseph Pesek

$\operatorname{LASRA}^{\circledast}$ 
Skin Structure

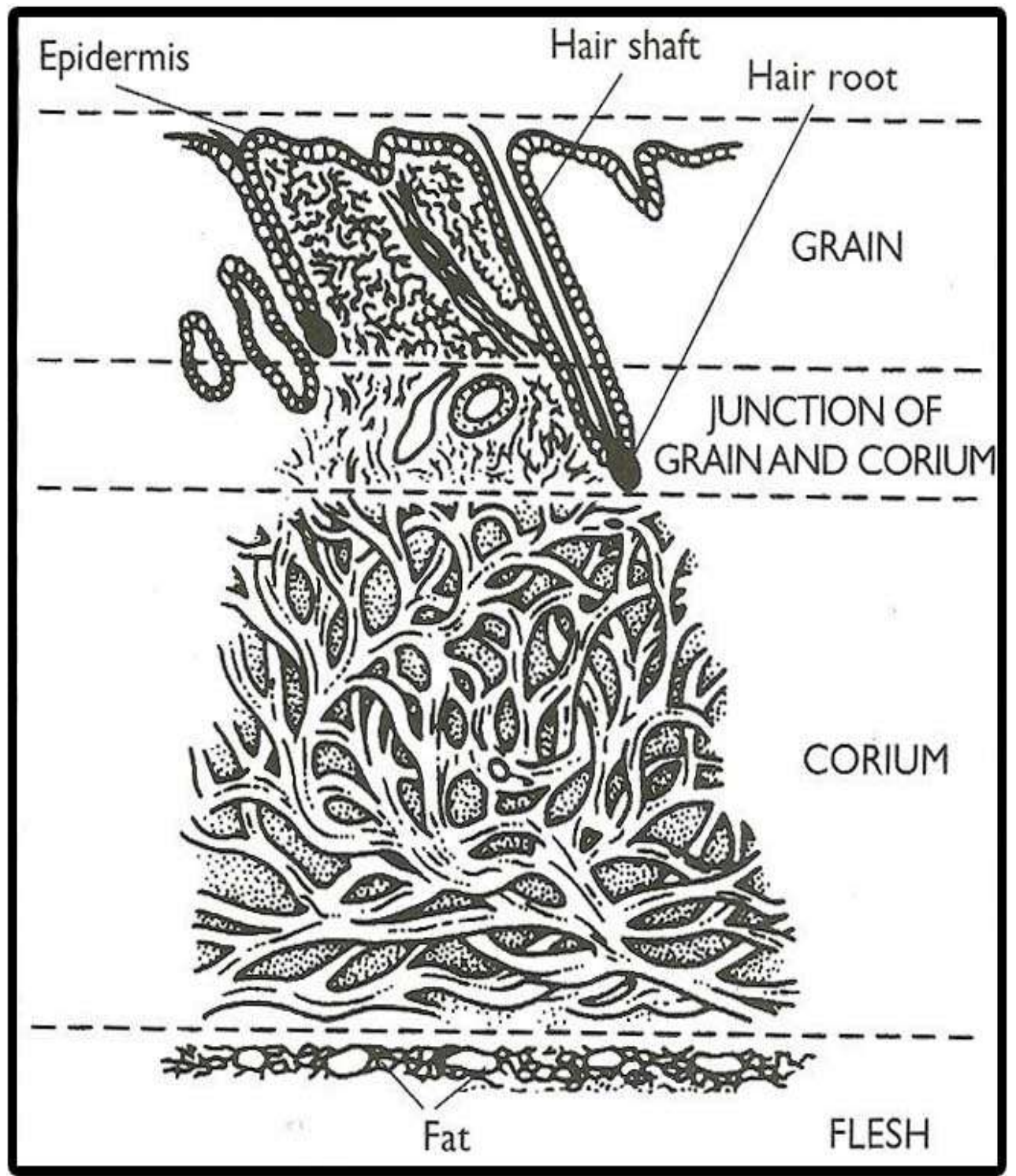

Polarizing Light Microscope Image of Skin

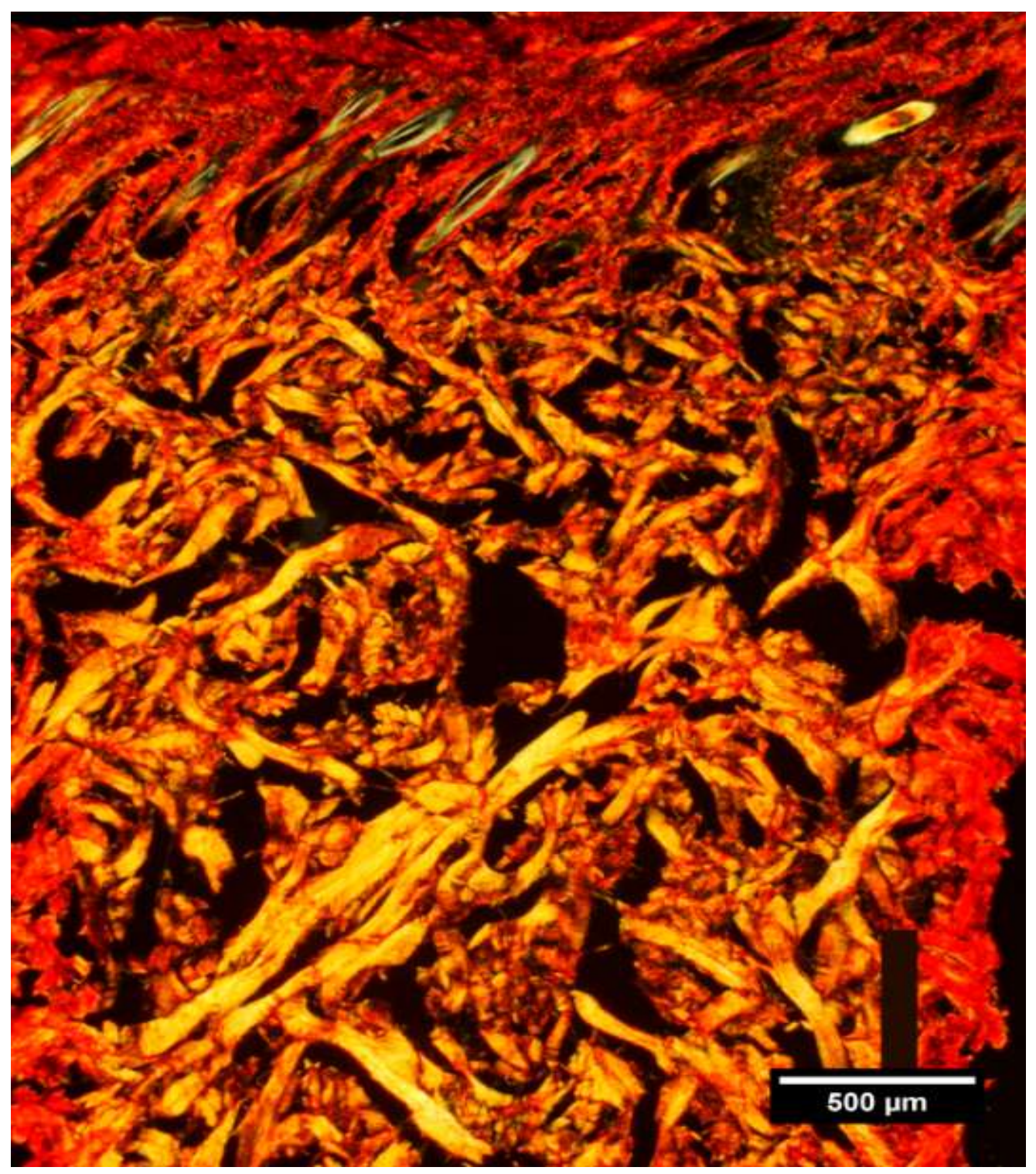


Skin

Microstructure: Fibres 


\section{Transmission}

Electron Microscopy (TEM)

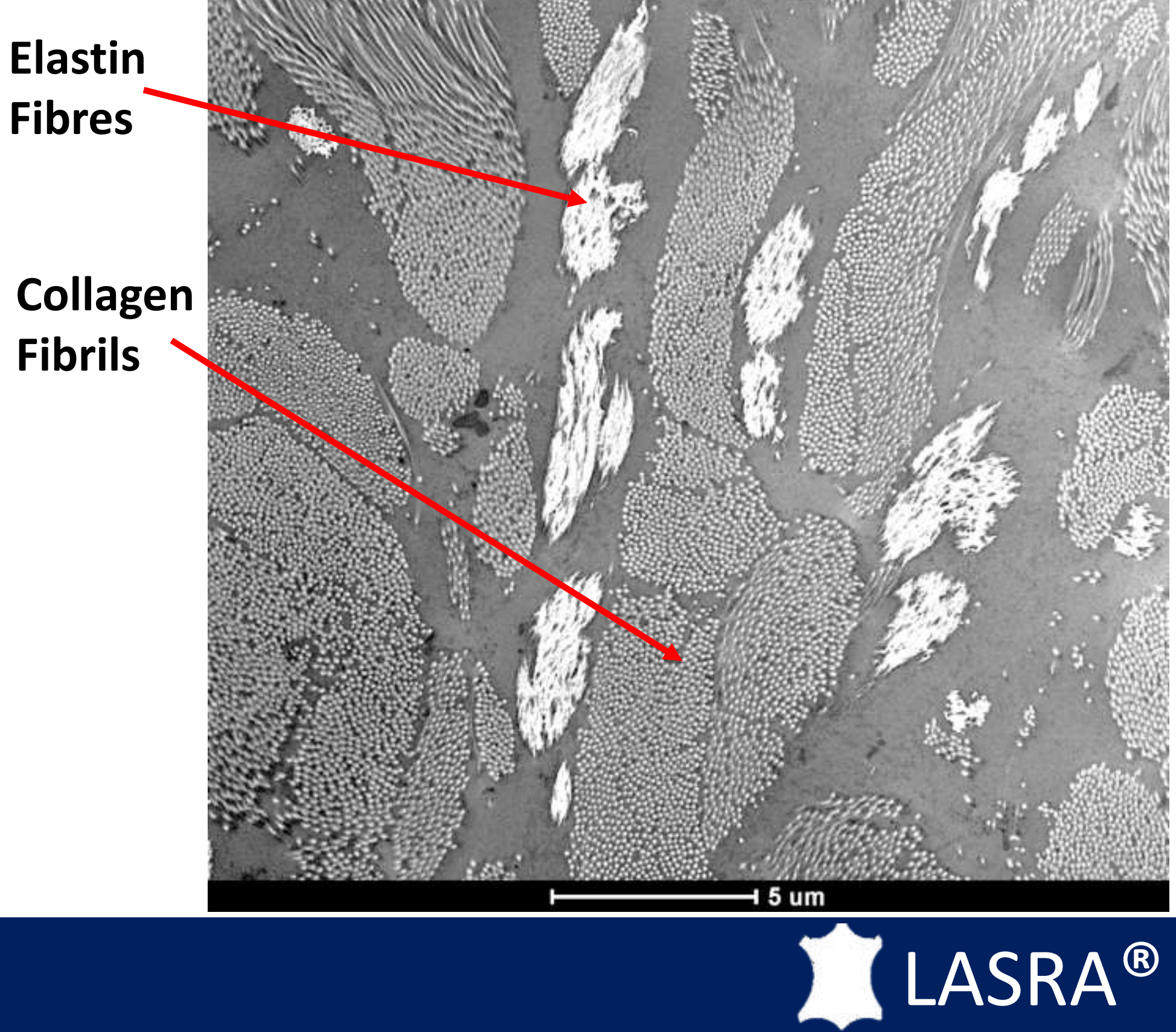




\section{Natural Crosslink Formation}

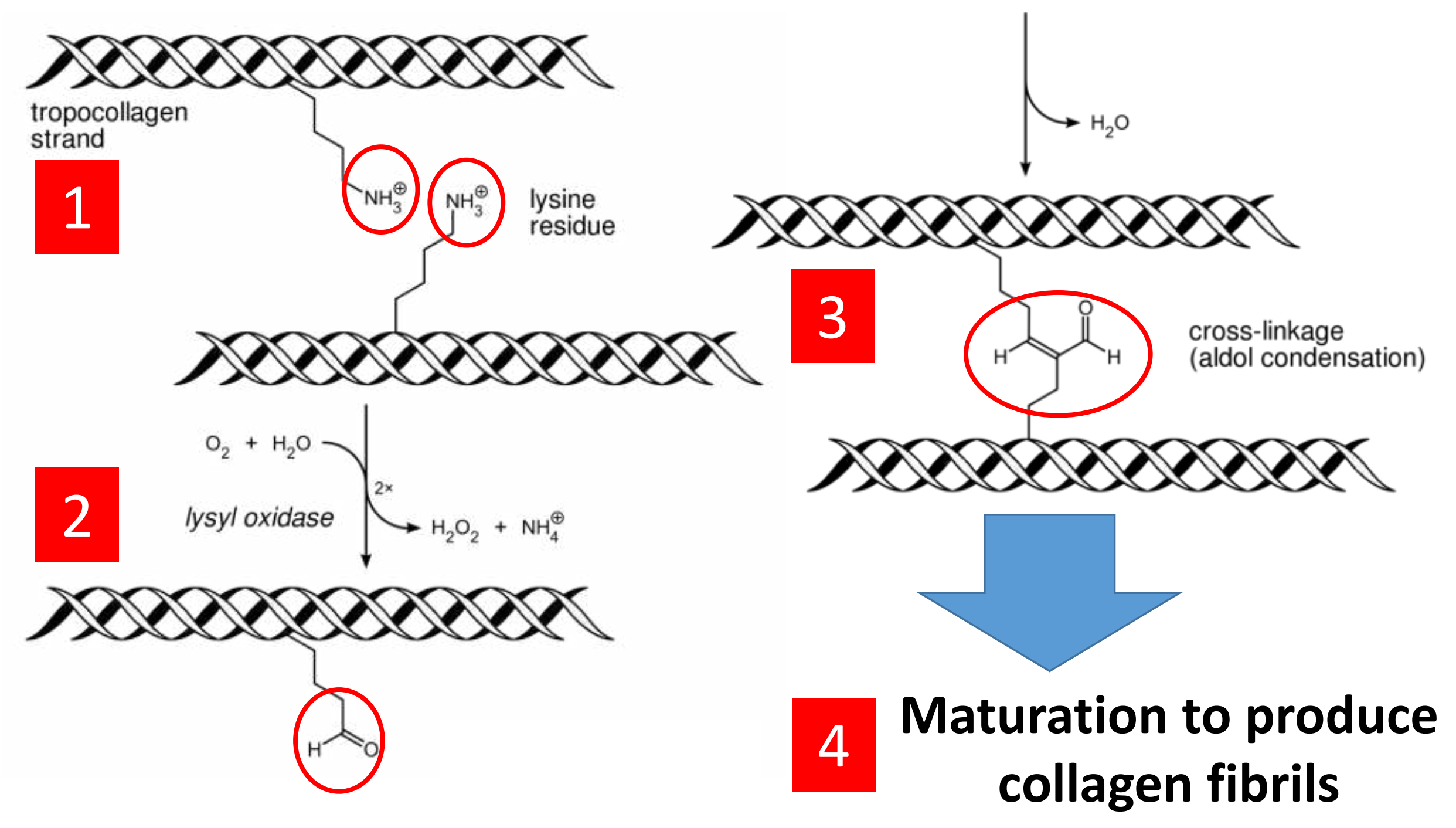

[LASRA ${ }^{\circledR}$ 


\section{Enzymatic Collagen Crosslinks}

$\mathrm{NH}_{\mathrm{H}_{2}}$

Lysinonorleuince (LNL)<smiles>N[C@@H](CCCCCNCCC(O)CC[C@H](N)C(=O)O)C(=O)O</smiles>

Hydroxylysinonorleuince (HLNL)<smiles>N[C@@H](CCCC(O)CCNCCC(O)CC[C@H](N)C(=O)O)C(=O)O</smiles>

Dihydroxylysinonorleuince (DHLNL)<smiles>NC(CCC(O)CNC(CCC[C@H](N)C(=O)O)c1nc(C[C@H](N)C(=O)O)c[nH]1)C(=O)O</smiles>

Histidinolysinonorleucine (HHL)<smiles>CC(=O)C(C)CCc1cnc(CCCCC(C)C(=O)O)cc1CCCC(C)C(=O)O</smiles>

Desmosine (Des)

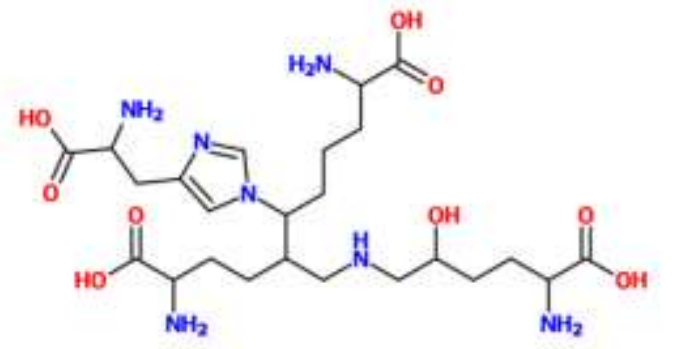

Histidinohydroxymerodesmosine (HHMD)

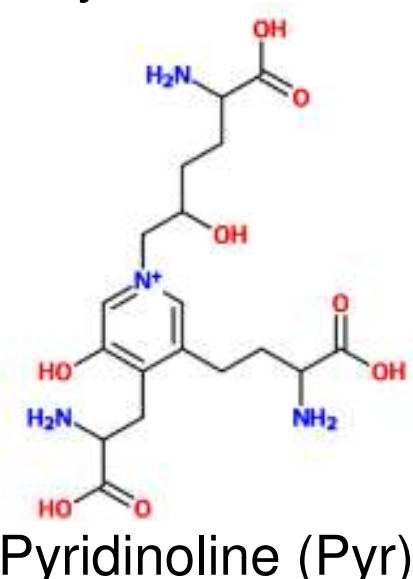




\section{Development of Collagen Crosslink Analysis}

A look into the last 60 years

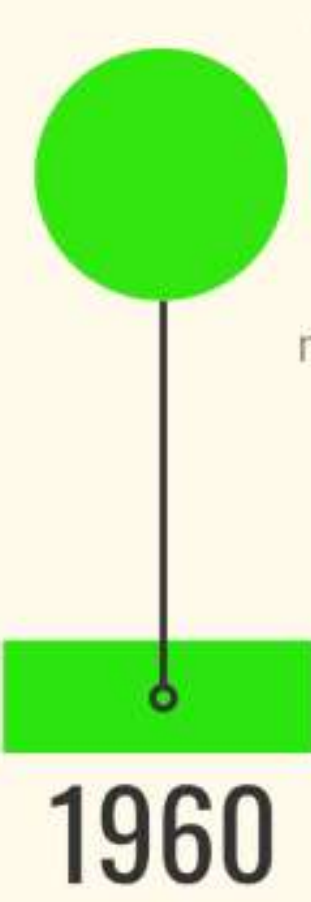

Hamilton

published the first

fully automatic

ion exchange

chromatography

Cation exchange

chromatography

using volatile

buffers with

radioactivity

monitoring (Bailey,

Robins, Eyre,

Mechanic)

1970

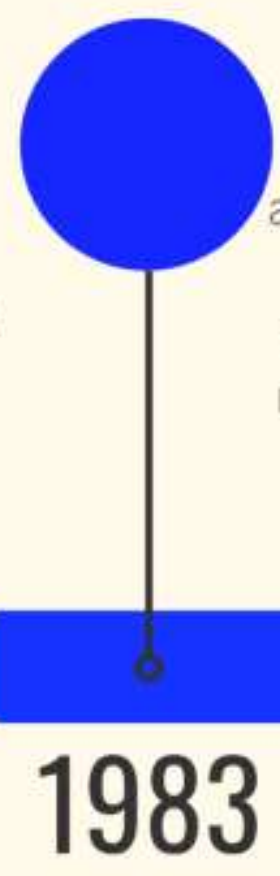

Eyre et al published the RP-HPLC of pyridinium crosslinks with fluorescence detection
Sims \& Bailey

published the analysis of collagen

crosslinks using

ion-exchange and

ninhydrin detection

\section{2}

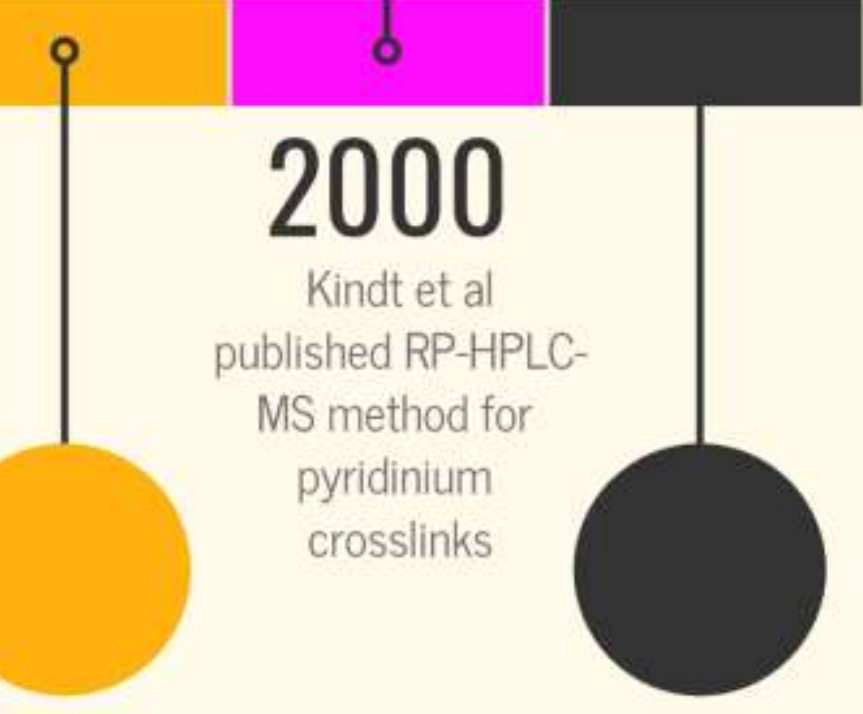

Gineyts et al published the first method for the

analysis of two

using ESI-LC-MS

2010 immature crosslinks

$\operatorname{ASRA}^{\circledR}$ 


\section{Crosslink Analysis Steps}

No change since 1960

\section{Stabilisation}

Reducible collagen crosslinks are stabilised using sodium borohydride

\section{Hydrolysis}

Crosslinks are released from the sample using acid or base hydrolysis at $105 \mathrm{C}$ for 24-48 hours

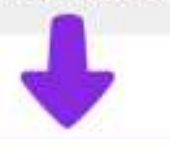

\section{Pre-Concentration}

Amino acids are removed using mini-glass column or SPE or gel filtration

$$
\text { Analysis - - - - - - - }
$$

Crosslinks are separated on a column the detected using UV, fluorescence or MS
Analysis has been significantly improved over time

\section{Separation}

Start: lon-exchange.

I Now: reverse phase.

\section{Detection}

I Start: Radioactivity

Now: Mass spectrometry

using UV, fluorescence or MS




\section{Ion Exchange Chromatography of Amino Acids}

\section{A Single Column, High Resolving, Fully Automatic Procedure}

PAUL B. HAMILTON

Alfred I. du Pont Institule of the Nemours Foundation, Wilmington 99, Del.

- A method for the quantitative determination of $10^{-8}$ mole of amino acids by ion exchange chromatography is described. A single 0.636- $X$ $125-\mathrm{cm}$. column packed with $17.5 \times$ $10^{-4} \mathrm{~cm}$. spherical particles is used; operating pressures are: approximately 450 p.s.i. The proicedure is fully automatic and the time for analysis through to arginine is 21 hours. Increased sensitivity anc improved resolution were obtained by optimizing variables related to the ion exchange resin (Dowex 50) column dimensions, and photometer flow cell. $0.01 \mathrm{Micro-}$ mole $\left(10^{-8}\right.$ mole) can be determined to within $\pm 5 \%$; the limit of determination is approximately $10^{-10}$ mole. By zero suppression and range expansion of the strip chart recorder,

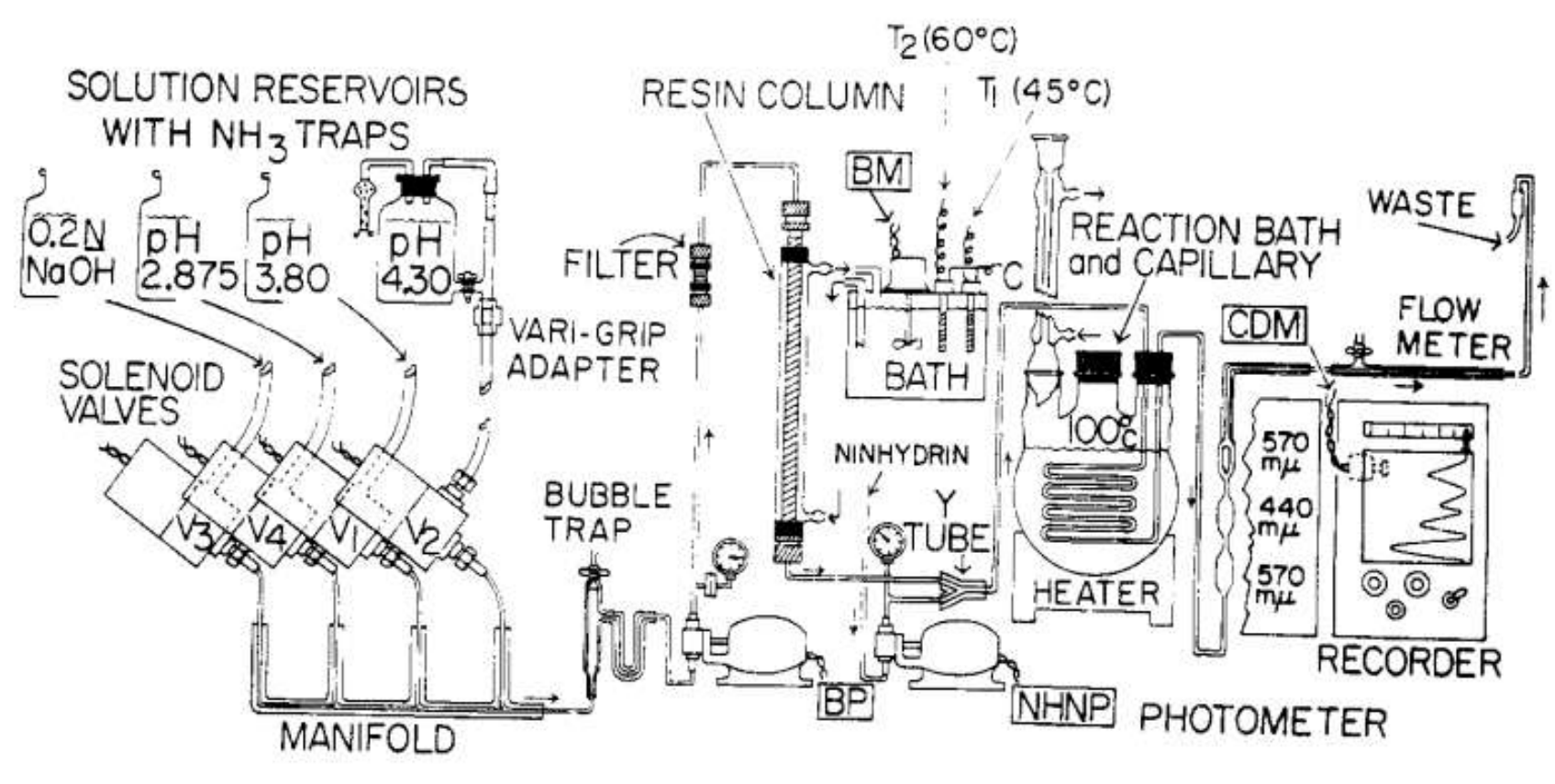

Figure 1. Schematic of apparatus

For description see text 


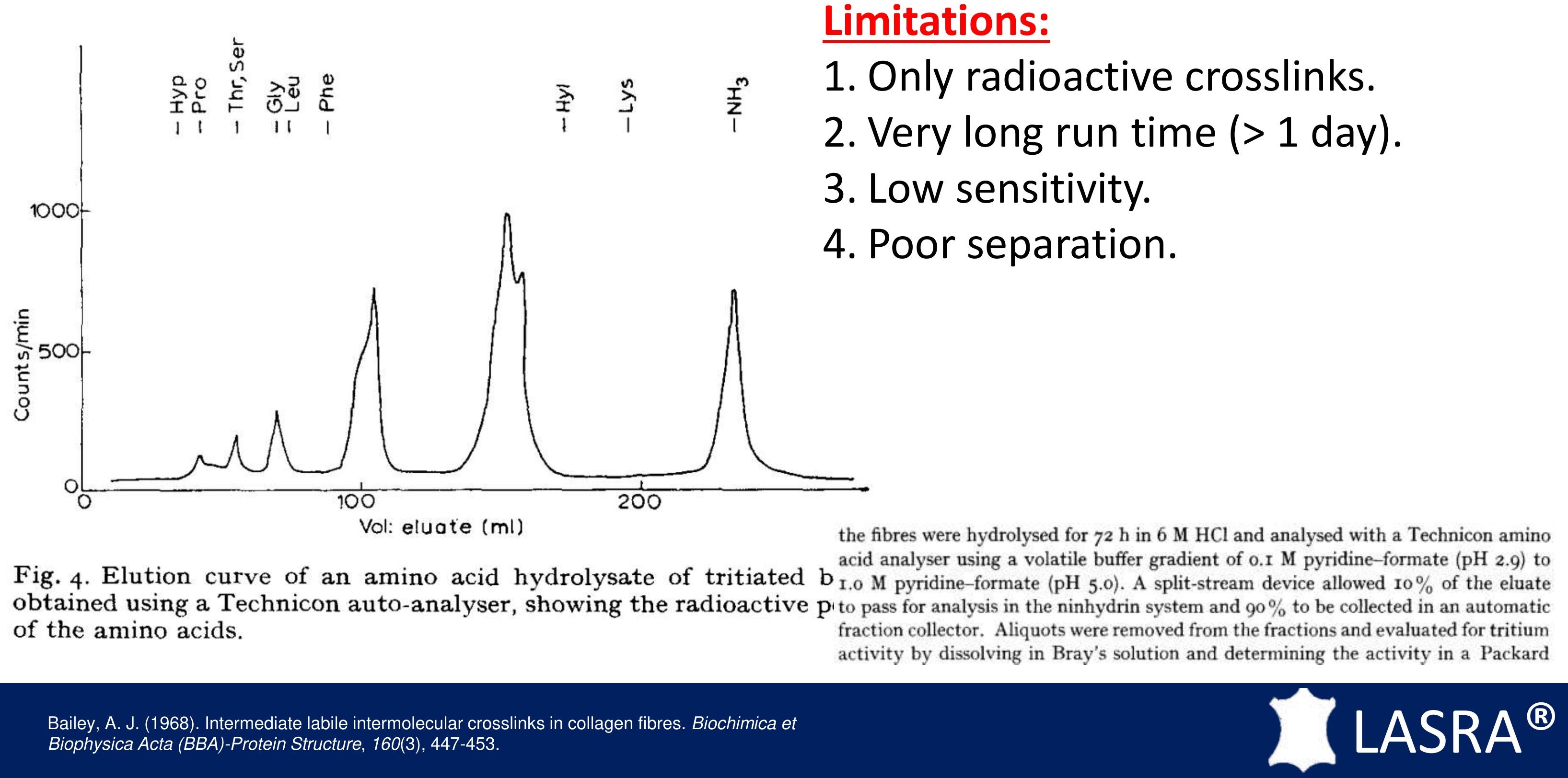


Quantitation of Hydroxypyridinium Crosslinks in Collagen by High-Performance Liquid Chromatography

David R. Eyre, ThOmas J. KoOB, and Kirk P. Van Nes

Children's Hospital and Harvard Medical School, 300 Longwood Avenue, Boston. Massa

Received August 5, 1983

\section{Limitations:}

1. ONLY for pyridinium crosslinks.

2. Strong ion pairing agent (TFA \& HFBA).

3. Fluorescence detection.

4. Linear response from $5 \mathrm{pM}$ to $120 \mathrm{pM}$

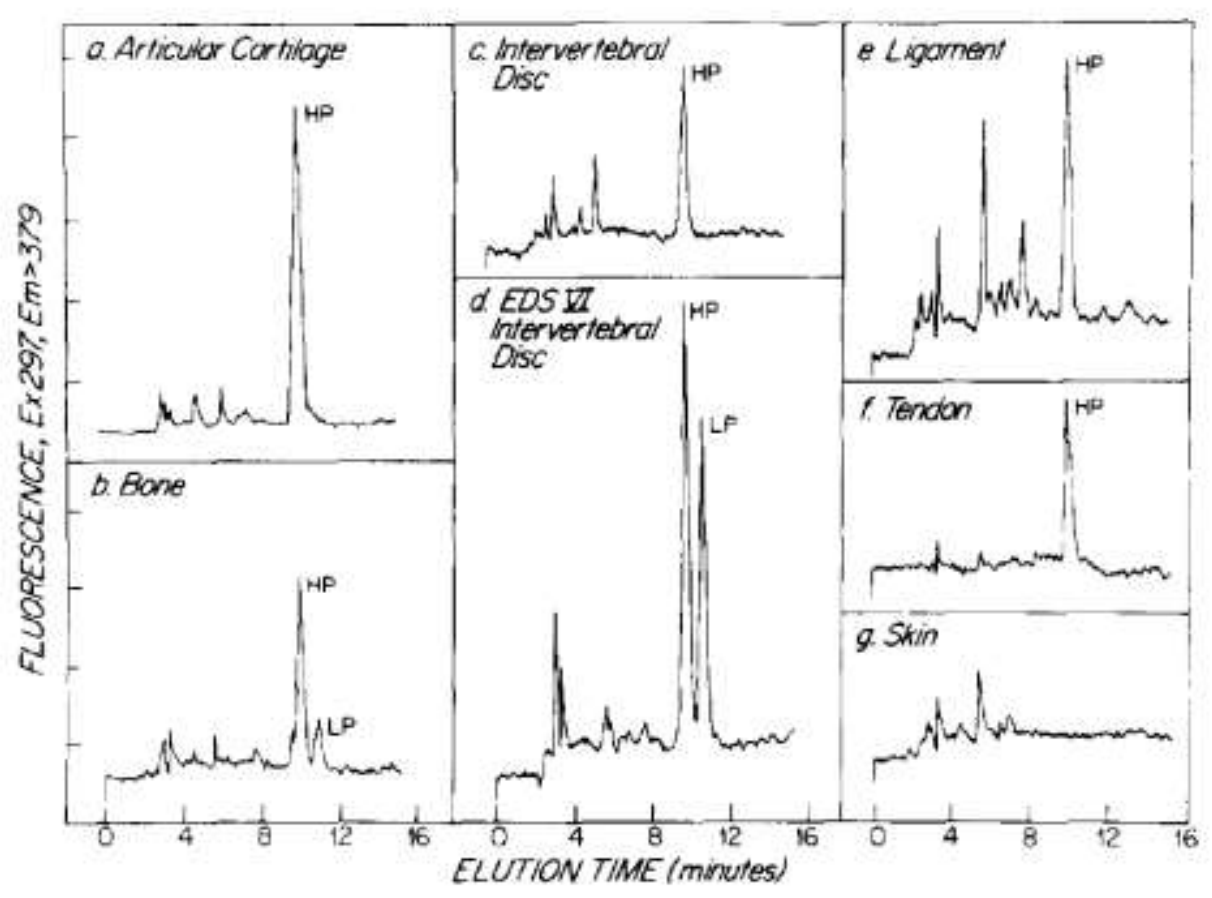

FIG. 3. Reverse-phase chromatography of HP and LP in hydrolysates of various human connective tissues. Chromatography conditions were similar to those in Fig. 2. monitoring for fluorescence. A 20- to 50- $\mu \mathrm{g}$ dry wt amount of each tissue was injected: (a) articular cartilage; (b) decalcified cortical bone; (c) annulus fibrosus; (d) annulus fibrosus from a patient with Ehlers-Danlos Syndrome type VI; (e) ligament: (f) tendon: and $(\mathrm{g})$ skin. 
Limitations:

1. Cation exchange chromatography (sodium citrate buffer) followed by ninhydrin detection.

2. Detection response based on leucine response.

3. Very long run time $>2$ hours.

4. Low sensitivity.
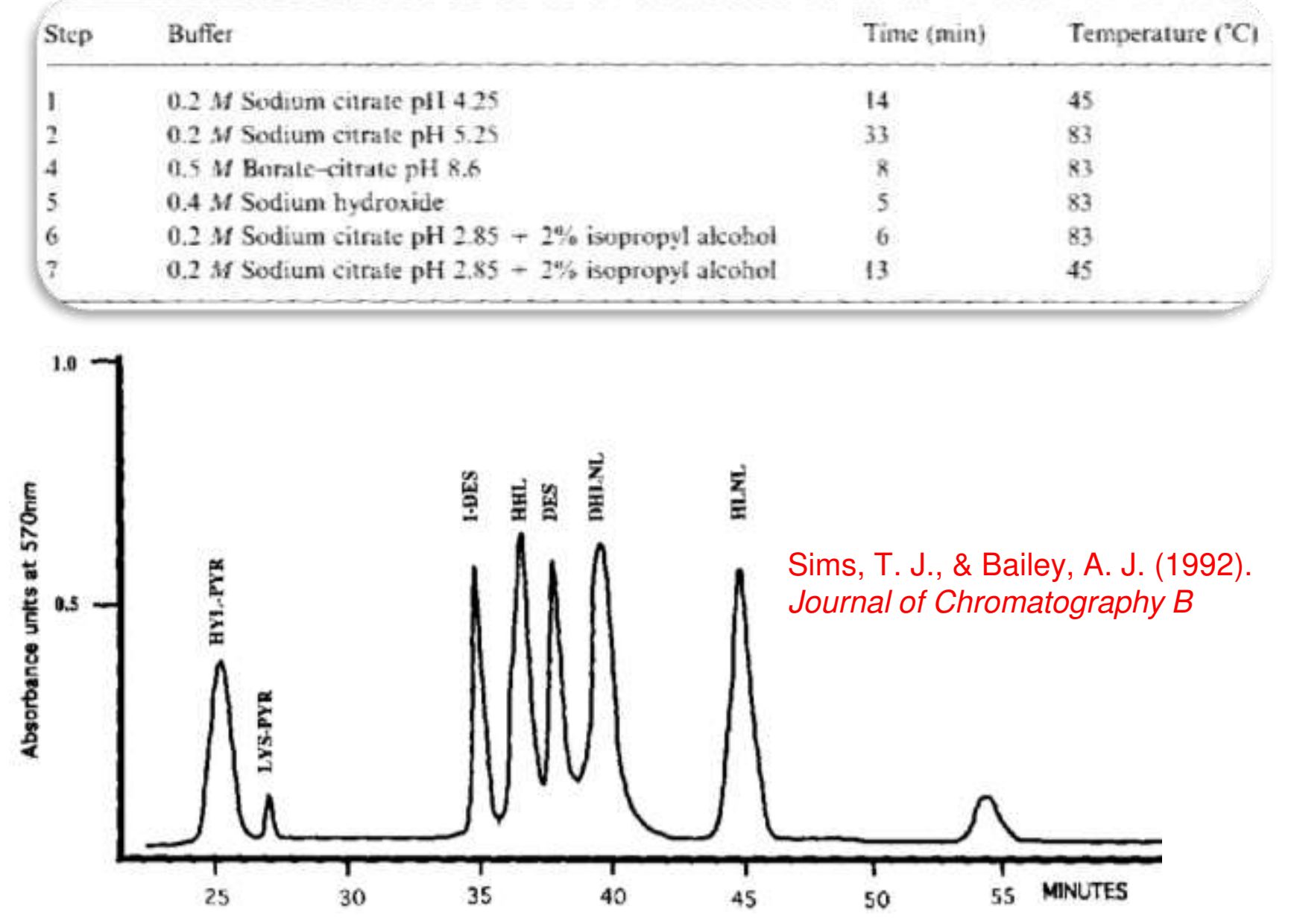

LASRA $^{\circledR}$ 


\section{Limitations:}

1. Strong ion pairing HFBA.

2. ONLY FOUR crosslinks.

3. HHL and HHMD NOT detected.

4. Long run time $\sim 40$ minutes.

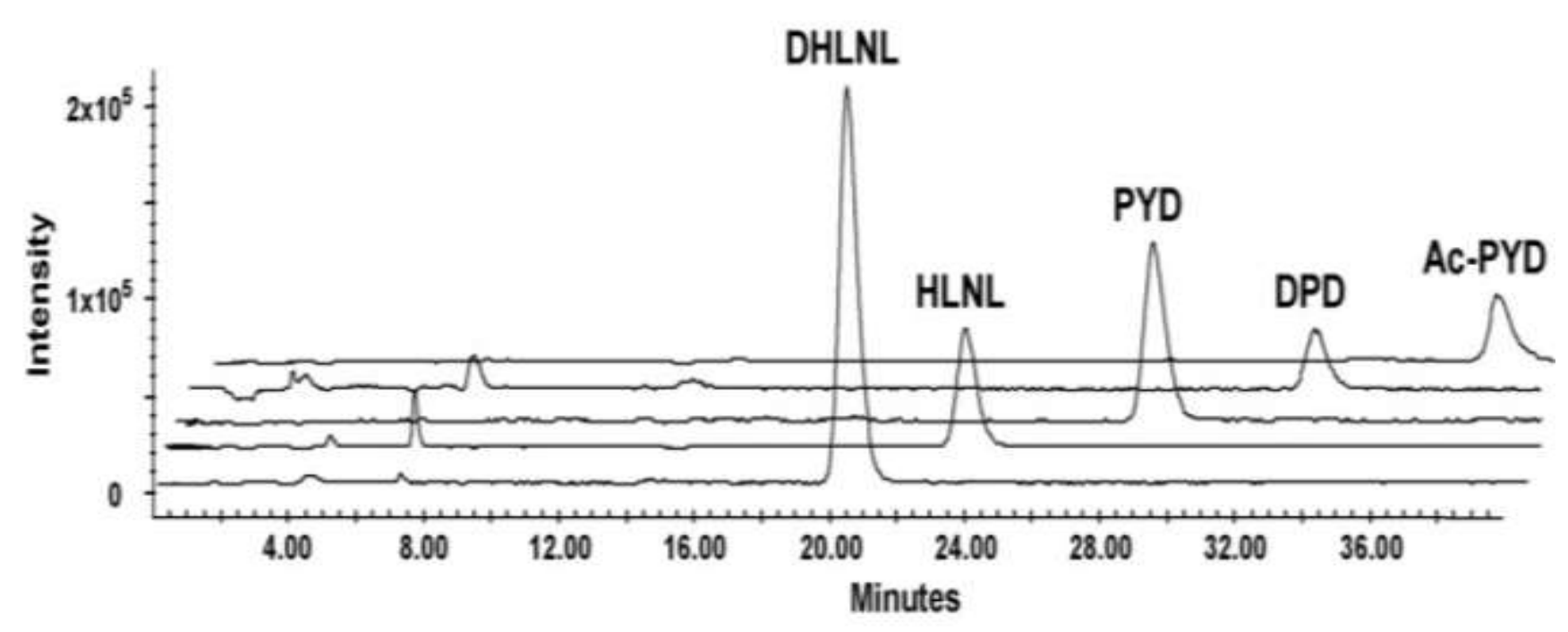




\section{Silica Hydride Stationary Phase!}

- Silica hydride is the same as ordinary silica but has hydride $(\mathrm{Si}-\mathrm{H})$ groups instead of silanols ( $\mathrm{Si}-\mathrm{OH})$.

- This makes it slightly hydrophobic producing "Aqueous Normal Phase (ANP)".

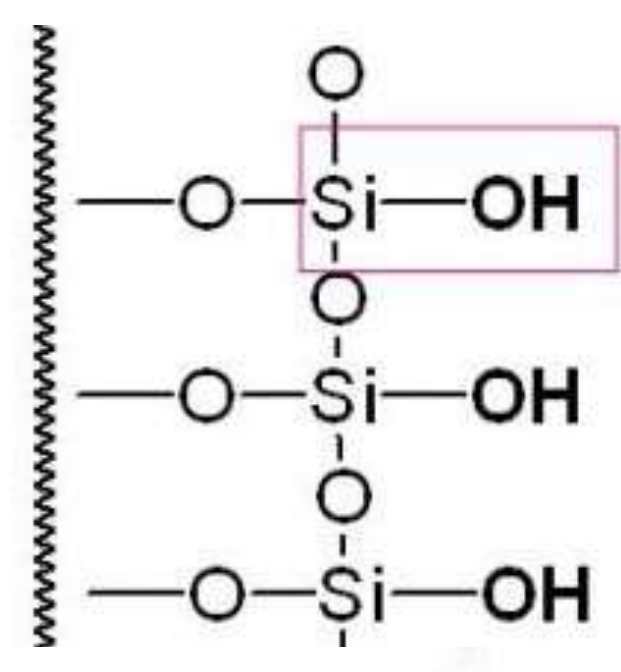

Ordinary Silica

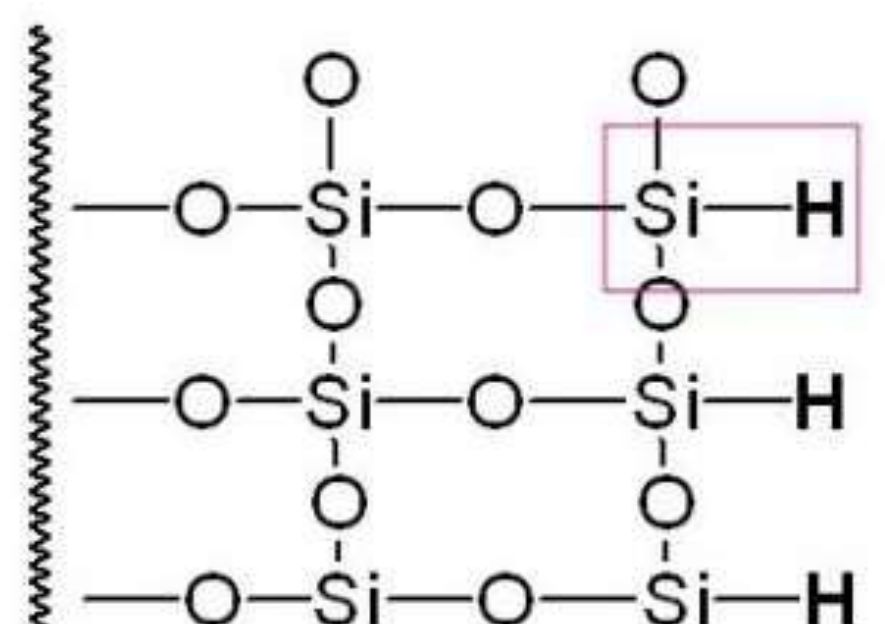

Silica Hydride 
Separation of 2.5 Crosslinks

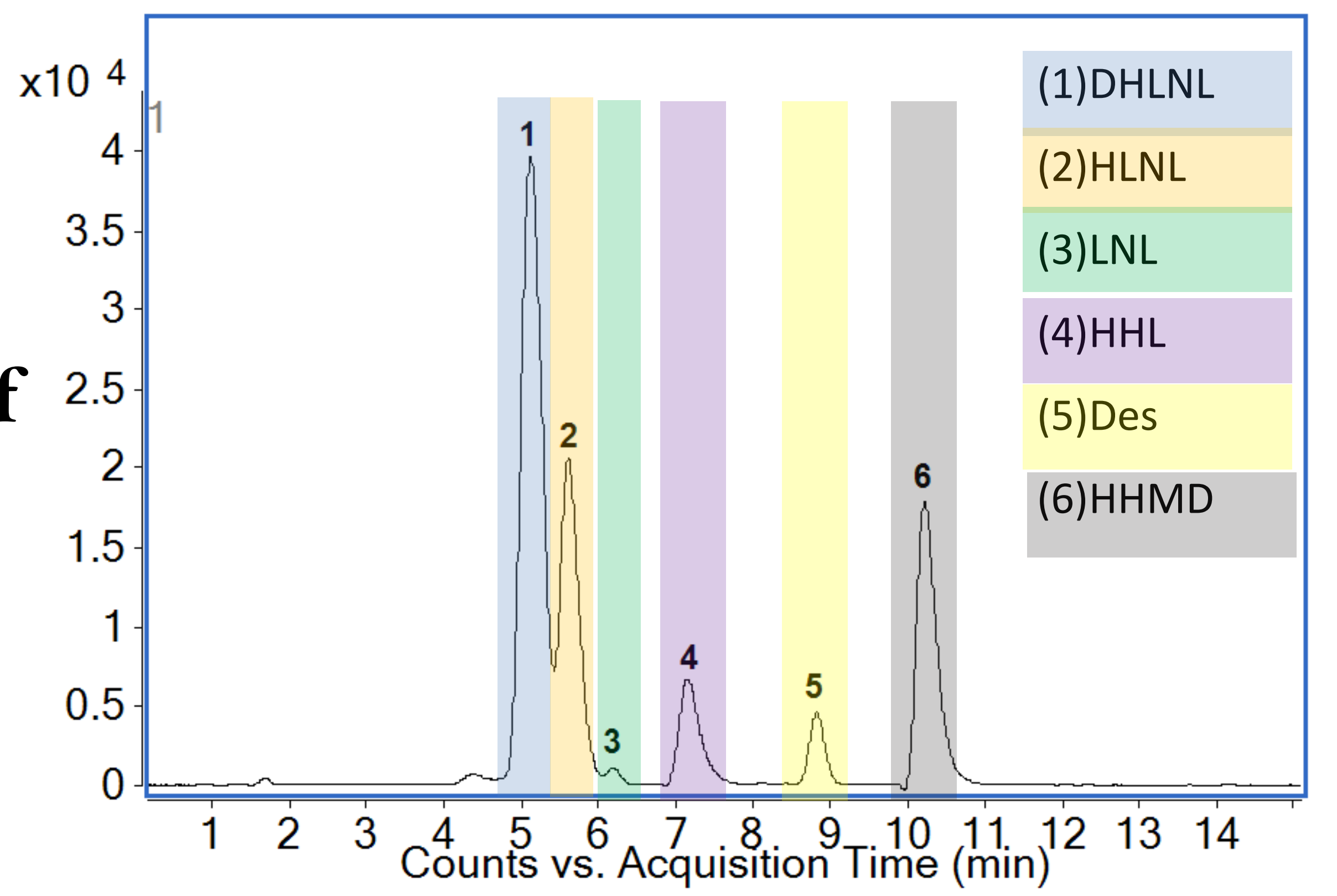




\section{Detection of Crosslinks by Mass Spectrometry}

\begin{tabular}{|l|c|c|c|}
\hline \multicolumn{1}{|c|}{ Crosslinks } & [M+1H $^{+}$ & {$[\mathbf{M + 2 H}]^{+2}$} & {$[\mathbf{M + 3 H}]^{+3}$} \\
\hline LNL & 276.3112 & 138.6610 & - \\
\hline HLNL & 292.2010 & 146.6030 & - \\
\hline DHLNL & 308.1537 & 154.5814 & - \\
\hline HHL & 445.2210 & 223.1100 & - \\
\hline Des & 526.2469 & 263.6280 & - \\
\hline HHMD & 574.3390 & 287.6733 & 192.1177 \\
\hline Pyr & 429.2081 & 215.1076 & - \\
\hline
\end{tabular}




\section{Collagen crosslinks in skins and hides}
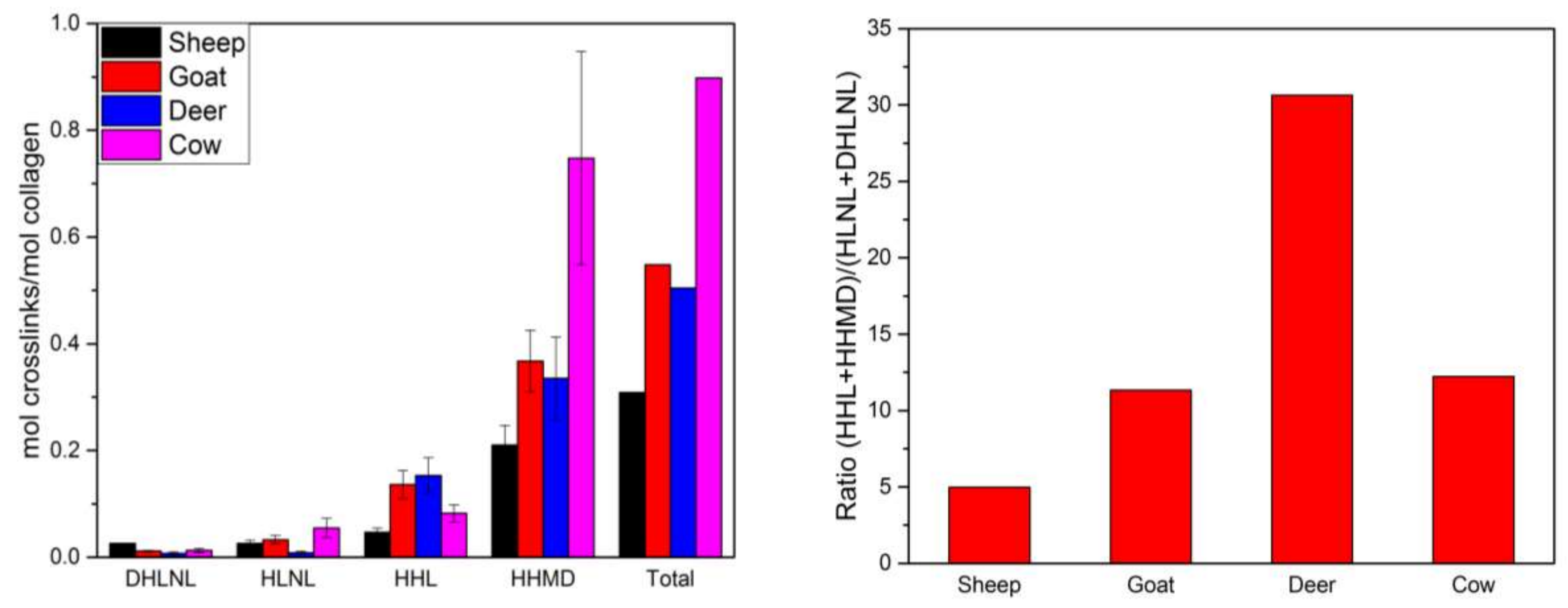
Quantitative and structural analysis of isotopically labelled natural crosslinks in type I skin collagen using LC-HRMS

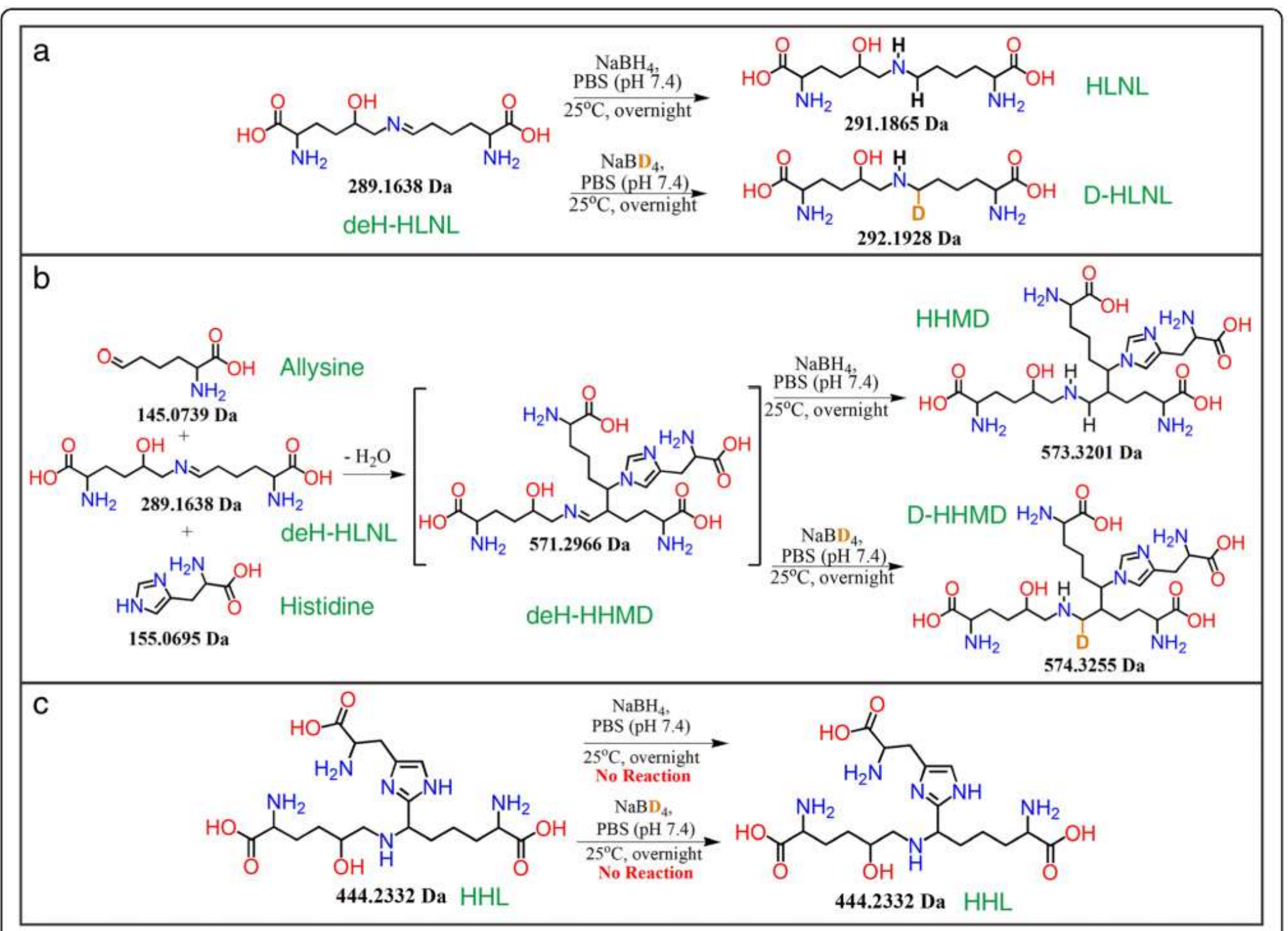

Fig. 1 Proposed reduction mechanism of the three natural crosslinks in collagen using $\mathrm{NaBH}_{4}$ or $\mathrm{NaBD}_{4}$. $\mathrm{a}$ The $\mathrm{C}=\mathrm{N}$ double bond in deH-HLNL is reduced to CH-NH or CD-NH in HLNL or D-HLNL, respectively. $\mathbf{b}$ The $\mathrm{C}=\mathrm{N}$ double bond in deH-HHMD can be reduced to form HHMD. However, the existence of deH-HHMD in vivo is yet debatable; it may be composed from deH-HLNL, histidine and allysine ex vivo during reduction. $\mathbf{c} H H L$ is not reducible (no reaction with $\mathrm{NaBH}_{4}$ or $\mathrm{NaBD}_{4}$ ). Theoretical molecular weight is calculated and presented below each molecule [34-36] 

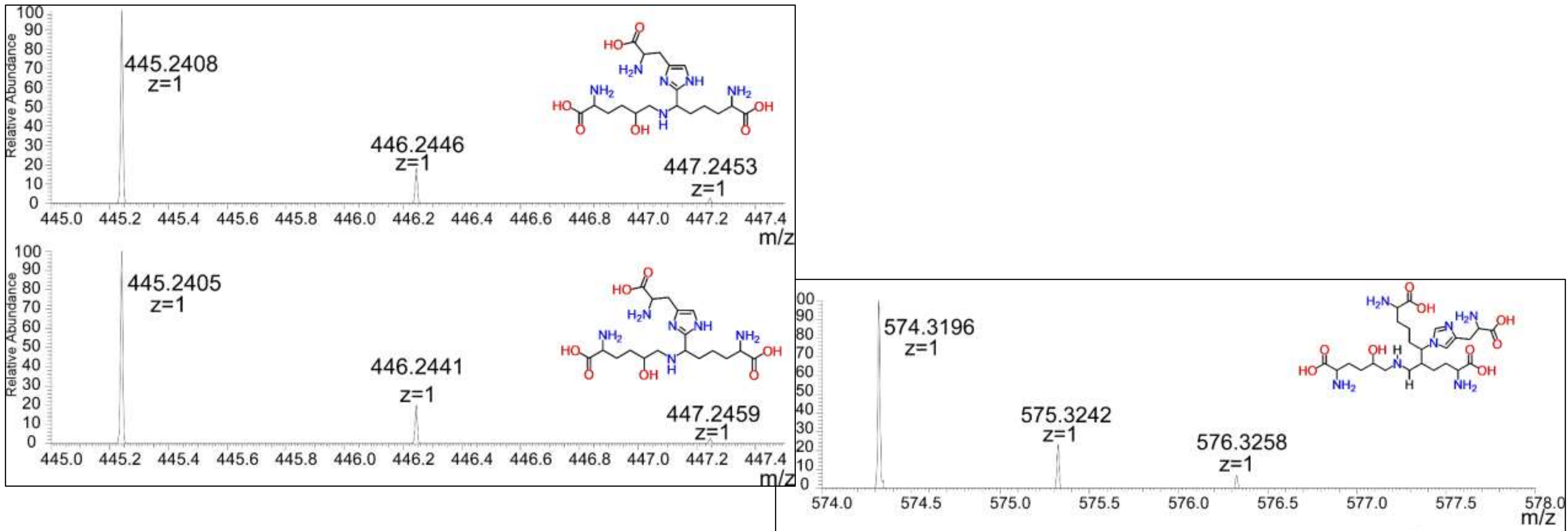

\section{Mass Spectra of isotopically labelled HHL and HHMD.}

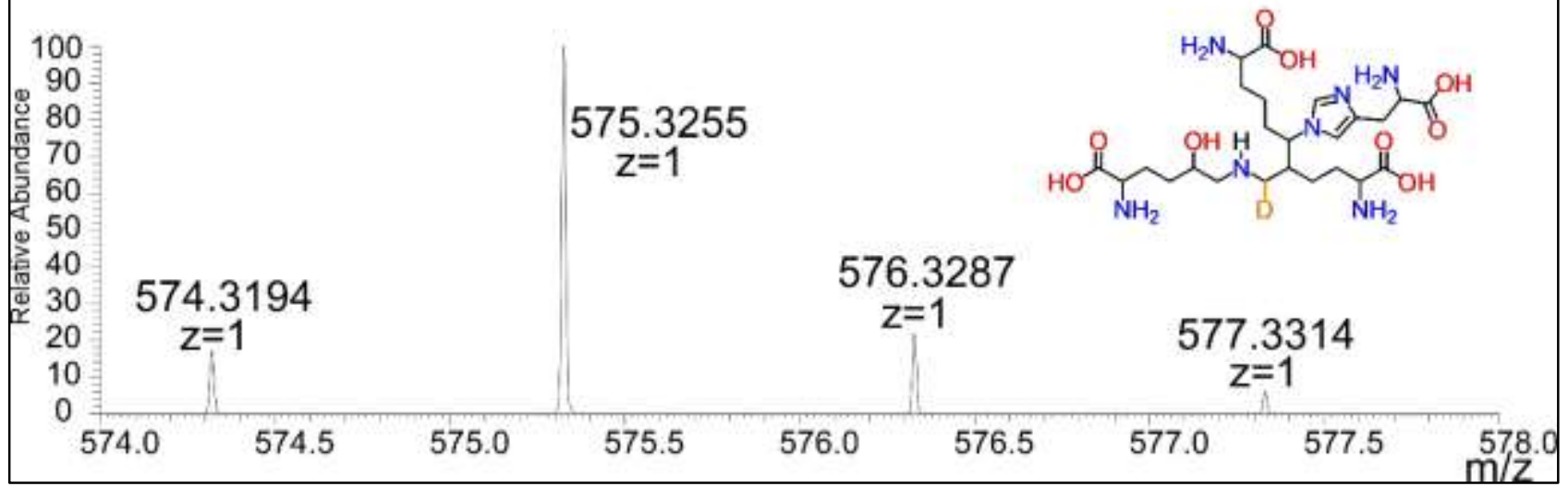

Zhang, Y., Naffa, R., Garvey, C. J., Maidment, C. A., \& Prabakar, S. (2019). Quantitative and structural analysis of isotopically labelled natural crosslinks in type I skin collagen using LC-HRMS and SANS. Journal of Leather Science and Engineering, 1(1), 10. 
T A B L E 2 Analysis of PYR and DPYR in animal skins and urine samples

\begin{tabular}{llll} 
Sample & Age & PYR $(\mathbf{m m o l} / \mathbf{m o l}$ collagen) & DPYR $(\mathbf{m m o l} / \mathbf{m o l}$ collagen) \\
Sheep skin $(\mathrm{N}=5)$ & $11-12$ months & $5.70( \pm 4.2 \%)$ & $0.82( \pm 7.5 \%)$ \\
Cow skin $(\mathrm{N}=5)$ & 5 years & $7.95( \pm 3.6 \%)$ & $1.41( \pm 8.1 \%)$ \\
Dog urines $(\mathrm{N}=3)$ & 3 years-Female & $0.75( \pm 2.2 \%)$ & $0.17( \pm 5.8 \%)$ \\
& & $60.2^{\mathrm{a}} \mathrm{pmol} / \mathrm{mL}$ urine $( \pm 8.3 \%)$ & $41.9^{\mathrm{a}} \mathrm{pmol} / \mathrm{mL} \mathrm{urine}( \pm 5.4 \%)$ \\
Rabbit urines $(\mathrm{N}=3)$ & Pregnant-Female & $110.2 \mathrm{pmol} / \mathrm{mL}$ urine $( \pm 6.0 \%)$ & $19.2 \mathrm{pmol} / \mathrm{mL} \mathrm{urine}( \pm 10.6 \%)$ \\
\hline
\end{tabular}

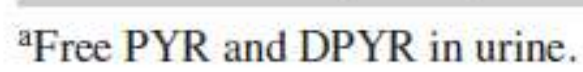


- Non-enzymatic collagen crosslinks are called advanced glycation end products (AGEs).

- AGE products derive spontaneously with time by further reactions of initial lysine (Lys) side-chain glycation adducts.

- Non-enzymatic glycation of collagen has long been associated with impaired tissues
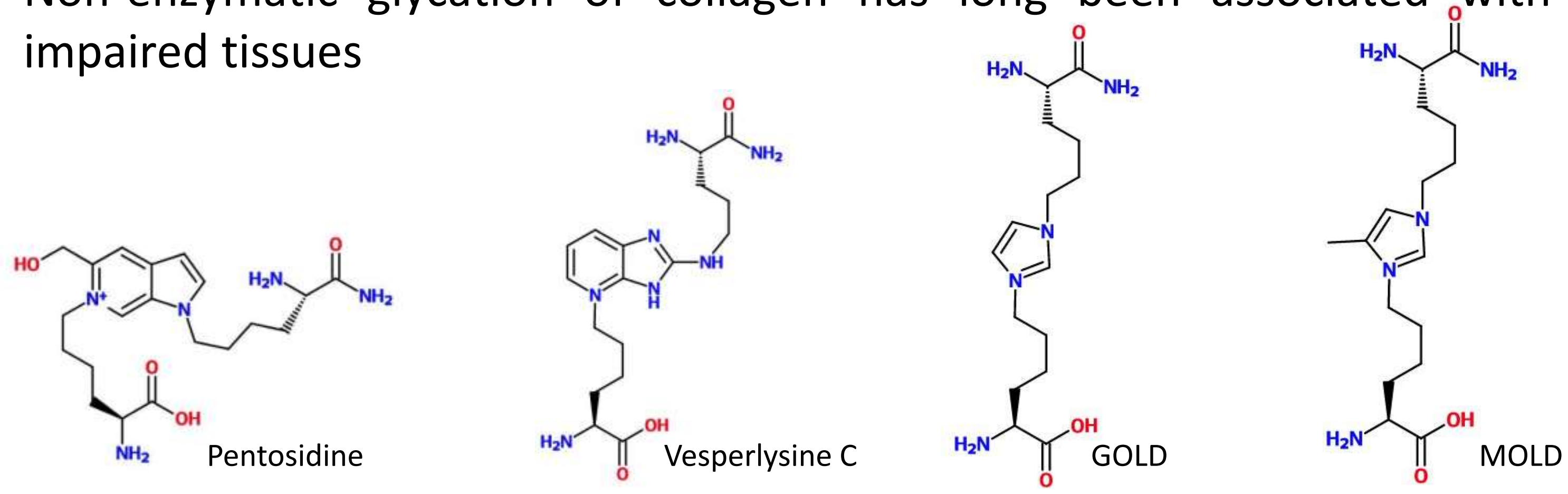


\section{Analysis of}

\section{Non-Enzymatic}

\section{Collagen}

\section{Crosslinks}

(Silica Hydride column using $30 \%$ acetonitrile in water and

$0.1 \%$ formic acid)
Pentosidine $(379.20 \mathrm{~m} / \mathrm{z})$

Vesperlysine $(407.20 \mathrm{~m} / \mathrm{z})$

GOLD $(327.20 \mathrm{~m} / \mathrm{z})$

MOLD $(341.20 \mathrm{~m} / \mathrm{z})$

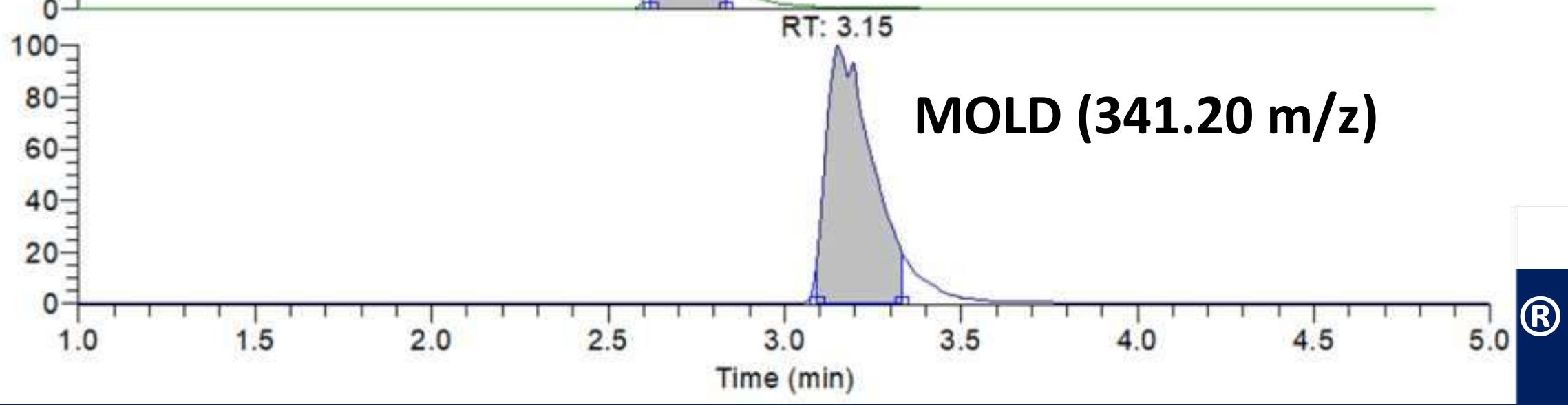


1. The fragmentation energy of HLNL, HHL and HHMD and advanced glycation end products optimised and their patterns measured on the mass spectrometry.

2. Silica hydride column was successfully used to rapidly and simultaneously analyse the collagen enzymatic and non-enzymatic crosslinks under both isocratic or gradient conditions.

3. For the first time, HHL, HHMD and AGEs were fully simultaneously separated and quantified using mass spectrometry.

4. Short run time ( 10 minutes) and high resolution and sensitivity were achieved on silica hydride column and mass spectrometry detection.

5. The developed method was successfully applied on several biological samples including skin, bone, cartilage, elastin and tendon. 


\section{Acknowledgment}

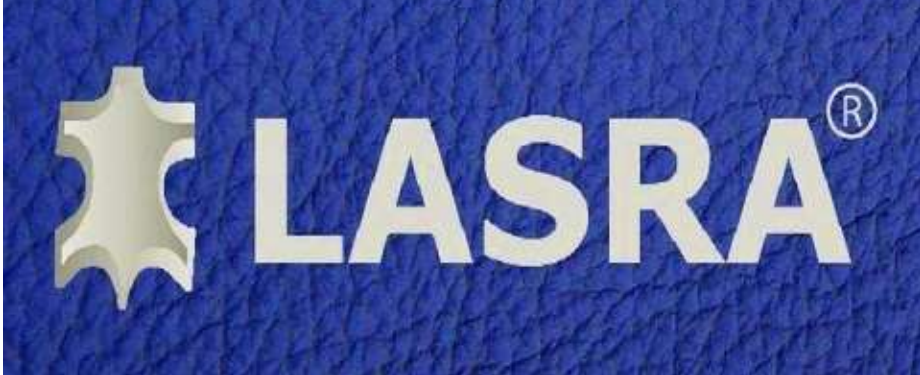

MINISTRY OF BUSINESS,

INNOVATION \& EMPLOYMENT

HITKINA WHAKATUTUKI

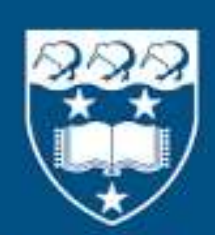

THE UNIVERSITY OF AUCKLAND Te Whare Wanangza o Tamaki Makaurau
San José State UN I VER S I TY 